\title{
The Attitudes of Demolition Contractors to Reusing Building Components: A Study in New South Wales, Australia
}

\author{
Reza Forghani ${ }^{1}$, Willy Sher ${ }^{1}$, Sittimont Kanjanabootra ${ }^{1}$, Yuri Totoev $^{1}$
}

\begin{abstract}
Over 16 million tonnes of construction and demolition waste (C\&D) is generated in Australia each year, and nearly $42 \%$ of this is disposed of in landfills. Waste disposal has a detrimental impact on the environment. Improved waste management practices are required to address sustainability goals. This study was conducted to investigate how demolition contractors' attitudes affect the ways they manage their operations and how these attitudes lead to the reuse of building components. The study was administered in New South Wales (NSW), Australia. A questionnaire survey focusing on "Reuse" was designed and issued to demolition contractors. Forty-two responses were collected from the respondents. The results showed that nearly $38 \%$ of demolition contractors did not have any form of strategy, guideline or goal for reusing building components, despite most of them viewing this as a fairly important measure. Additionally, the study elicited other relevant factors including the main reasons for reusing building components and the significance of cooperating with building designers. This study concluded that, as demolition contractors play a pivotal role in the management of $C \& D$ waste, more attention is needed to improve their overall practices.
\end{abstract}

Keywords: Demolition Contractors; Building Components; Reuse;

\section{Introduction}

Disposal of Construction and Demolition (C\&D) waste impacts on the environment in many ways. For example, it leads to soil and groundwater contamination and imposes pressure on natural resources (Peng et al., 1997, Forghani et al., 2017). In Australia, over 16 million tonnes of C\&D waste is generated in each year and nearly $42 \%$ of that is disposed of in landfills (EPHC, 2010). The state of New South Wales (NSW) generates one-third of national C\&D waste (Pickin, 2013). This highlights the immediate needs for sustainable and efficient waste management practices. In the hierarchy of waste management (Figure 1), "Reuse" is identified as the most efficient measure where prevention is not possible (Papargyropoulou et al., 2014). It takes preference over recycling and recovery as it minimizes the need for some waste management practices such as waste segregation and transportation. Reusing building components can help to control the generation of C\&D waste and to reduce the cost of new building construction (Huuhka et al., 2015, Laefer and Manke, 2008). In the building industry, successful reclamation of building components is highly dependent on the practices of demolition contractors. They need to disassemble building components so that they can be reused with minimum modification and refurbishment (Randell et al., 2014). 
This study was conducted to determine the extent to which demolition contractors considered disassembly of components in their demolition practices. It explored whether they have strategies, procedures or guidelines in place that would enable components to be reused. A questionnaire was administered to demolition contractors in NSW who were licensed by "SafeWork NSW" (2018) (A government organization responsible for regulating workplace safety). Forty-three demolition contractors responded to the questionnaire. Details of the respondents and the questionnaire are given in the methodology section.

Figure 1: Hierarchy of waste management (Papargyropoulou et al., 2014)

\section{Attitudes of demolition contractors}

Behavior of individuals towards their surroundings can be defined by understanding their attitudes (Kulatunga et al., 2006). Attitudes can define the way people prioritize their surroundings (Teo and Loosemore, 2003). Also, it has been indicated that the attitude of individuals can be developed and redirected, for example, by understanding the correct order of a specific procedure (Spooncer, 1992).

The attitude of parties involved in the building industry has a great influence on waste management (Kulatunga et al., 2006). It has been indicated that changing attitude is more effective than changing techniques in waste management (Skoyles and Hussey, 1974). Particular attitudes in the building industry have been identified as one of the sources of difficulties in waste management (Teo and Loosemore, 2001).

Demolition contractors are generally involved in projects as a sub-contractors (Diven and Shaurette, 2010). Also, it has been found that subcontractors use inefficient waste management procedures due to several reasons including limitations in time and budget (Jayawardane, 1994). Accordingly, by investigating the attitude of demolition contractors towards waste management, more efficient practices can be identified.

\section{Methodology}

Selecting an appropriate method for data collection is regarded as one of the most important steps in a research study. In this study, the attitudes of respondents have been investigated throughout NSW. A large volume of data can be efficiently extracted through questionnaire surveys with minimum cost (Al-Tmeemy et al., 2012). Different 
types of structured questions can be provided in this manner. For example, Likert scale questions have been widely used in several studies to investigate the perception of respondents (Khalfan et al., 2015, Osmani et al., 2008). Accordingly, this method of data collection was used to investigate the attitudes of demolition contractors in NSW.

There are over 1100 demolition contractors in NSW. A list of active demolition contractors licensed by SafeWork NSW was extracted from the SafeWork website. The sample size was estimated 218 for the finite population (Berenson et al., 2012). The questionnaire was distributed using an online survey provider (SurveyMonkey). Over a period of two months in 2018, 43 responses were received, representing a 19.2\% response rate. All in all, 40 responses provided valid information and three were discarded as they were incomplete. The construction industry is well-known for its low response rate and 20-30\% response rate is considered reasonable (Al-Tmeemy et al., 2012, Dulaimi et al., 2003).

The survey contained demographic questions which were designed to determine the eligibility of respondents as demolition contractors in NSW and to clarify the individuals best placed to respond as representatives of these companies (Akinade et al., 2017, Lingard et al., 2000). The respondents in the demolition companies identified themselves as shown in Table 1.

Table 1: Description of Respondents

\begin{tabular}{|lcc|}
\hline Respondent & Number of Responses & Percentage \\
\hline Supervisor & 7 & 17.5 \\
Project and assistant manager & 10 & 25 \\
Civil engineer & 3 & 7.5 \\
Demolition practitioners and license holder & 15 & 37.5 \\
Licensed asbestos removalist & 2 & 5 \\
Other & 3 & 7.5 \\
Total & 40 & $100 \%$ \\
\hline
\end{tabular}

Osmani et al. (2006) and Lingard et al. (2000) determined the main concerns in C\&D waste management in terms of attitude and perception of contracting companies. These concerns were addressed in the questionnaire and are as follows:

- Views of demolition contractors about the practice of reuse in terms of feasibility, cost, and overall significance,

- The significance of cooperation with other involved parties in facilitating the practice of reuse,

- Availability of a strategy or a guideline for the practice of reuse,

- Influence of involved parties for this practice, and determining the main reasons for assuming the practice of reuse.

Likert-type scale, multiple choice, and ranking questions were used in the questionnaire.

\section{Results}

The years of experience of respondents are as follows: $72.5 \%$ over 10 years, $20 \%$ had 5 to 10 years, and $7.5 \%$ under 5 years. The majority of respondents had over 10 years of experience in demolition work, which attests to the validity and credibility of 
data collected.

The respondents were asked to determine whether pursuing the practice of reuse is associated with the potential cost of demolition. The majority of respondents $(87.5 \%)$ highly emphasized the significance of "cost" when it comes to pursuing the practice of reuse. However, their answers showed that they evaluate the feasibility of reusing components from their projects less frequently (Table 2).

Table 2: Importance of reuse \& frequently of evaluating the feasibility of reuse

\begin{tabular}{|c|c|c|c|c|c|c|}
\hline \multirow[b]{2}{*}{$\begin{array}{l}\text { Pursuing practice of reuse } \\
\text { depends on potential cost }\end{array}$} & $\begin{array}{l}\text { Strongly } \\
\text { disagree }\end{array}$ & Disagree & Neutral & Agree & $\begin{array}{c}\text { Strongly } \\
\text { agree }\end{array}$ & Total \\
\hline & $2.5 \%$ & $5 \%$ & $5 \%$ & $52.5 \%$ & $35 \%$ & $100 \%$ \\
\hline \multirow[b]{2}{*}{$\begin{array}{l}\text { Evaluating the feasibility of } \\
\text { practice of reuse }\end{array}$} & Never & Rarely & Sometimes & Often & Always & Total \\
\hline & $2.5 \%$ & $5 \%$ & $37.5 \%$ & $27.5 \%$ & $27.5 \%$ & $100 \%$ \\
\hline
\end{tabular}

They were also asked whether cooperation with other construction professionals such as building designers could contribute to the reusability of building components. Their answers showed a high level of agreement (90\% agree and strongly agree) with this statement. However, fewer respondents (15\% always and $37.5 \%$ often) claimed that they cooperated with other parties (Table 3).

Table 3: Importance of cooperation for improving reusability of building components \& the actual cooperation which takes place

\begin{tabular}{|lcccccr|}
\hline \multirow{2}{*}{$\begin{array}{l}\text { Cooperation helps } \\
\text { improving reusability }\end{array}$} & $0 \%$ & $0 \%$ & $10 \%$ & $57.5 \%$ & $32.5 \%$ & $100 \%$ \\
\cline { 2 - 7 } & Strongly disagree & Disagree & Neutral & Agree & Strongly agree & Total \\
\cline { 2 - 7 } Actual cooperation & $5 \%$ & $15 \%$ & $27.5 \%$ & $37.5 \%$ & $15 \%$ & $100 \%$ \\
\hline
\end{tabular}

The majority of the demolition contractors surveyed $(87.18 \%)$ viewed the practice of reuse as an important, very important and fairly important measure, while only $12.82 \%$ viewed it as a slightly important measure. It is interesting to note that $37.5 \%$ of demolition companies indicated that they do not have any strategy, guideline or goal for the practice of reusing building components.

Participants were asked to rank the reasons for reusing building components (Table 4).

The average ranking was calculated by the following equation (Armatys et al., 2010):

Average Ranking $=\frac{X_{1} W_{1}+X_{2} W_{2}+\cdots+X_{n} W_{n}}{\mathrm{~N}}$

Where, $W$ is weight of ranked option, $X$ is number of responses, and $N$ is total number of respondents.

Table 4: Ranking of the main driving factors for pursuing the practice of reuse

\begin{tabular}{|lcc|}
\hline Reasons & Rank & Score \\
\hline Environmental factors & 1 & 3 \\
Financial factors & 2 & 2.81 \\
Client's request & 3 & 2.49 \\
\hline
\end{tabular}




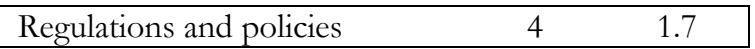

As shown in Table 4, environmental factors followed by financial factors are the main reasons mentioned by demolition contractors for reusing building components. The least important measures were the client's requests and regulations.

\section{Discussion}

From the collected data it can be deduced that there is a lack of attention towards the practice of reuse among demolition contractors in NSW. While they highly indicated "cost" as a significant factor for undertaking the practice of reuse, they appear not to evaluate the feasibility of this practice. This may be due to the fact that disassembling building components for reuse can be a challenging practice for them (Nakajima and Russell, 2014). They may, therefore, be reluctant to evaluate the feasibility of this practice in the first place. It can be argued that as each project has its unique characteristics, a specific effort is needed to evaluate its cost and benefits of the project. Cooperation with the other parties involved in building industry is regarded as a thoroughly constructive factor for improving the reusability of building components. However, there appears to currently be little cooperation between demolition contractors and other parties. This can be attributed to the fact that there might not be effective systems or mechanisms for these parties to effectively communicate and interact with each other.

The lack of strategies, guidelines or goals for the practice of reuse was also noted among the considerable number of respondents in NSW. Two possible scenarios can be derived from this fact: firstly, they consider the practice of reuse in their projects, but they do not have or follow any framework for their practice; secondly, they do not consider the practice of reuse in their projects thoroughly. Either of these two situations shows the necessity of providing an appropriate framework in this field to guide and inform demolition contractors and clarify the potential benefits for them.

The collected data indicated that if demolition contractors attempt to reuse building components, it will be mainly for environmental and financial reasons. It also showed that the regulations and policies were not a driving factor in this practice.

As mentioned earlier, the attitudes of individuals can be reflected in their behaviors. Hence, it can be argued that the attitudes of demolition contractors play a pivotal role in their actual waste management practices. Although their practices may be influenced by several aspects, one of the most preponderant aspects stems from their attitudes.

\section{Conclusion}

This study explored the attitudes of demolition contractors towards the practice of reusing building components. The results showed that demolition contractors appreciate the importance of reusing building components, but their actual practices still lag behind their opinion.

Similarly, demolition contractors acknowledged the significance of cooperating with other involved parties to improve the reusability of building components. However, the survey results showed that such cooperation is infrequent. Providing an appropriate 
communicative and interactive system for those involved in the building industry can assist in addressing this issue.

Furthermore, this study found that environmental considerations and profitability were the main reasons demolition contractors noted for conducting demolition activities in ways that facilitate their reuse. Regulations and policies were ranked as the least influential measures in this regard.

To reiterate, this study emphasized the important role of demolition contractors for the practice of reusing building components. The data collected from demolition contractors also showed that insufficient attention is paid towards reusing building components when it comes to actual practice.

\section{References}

2018. SafeWork [Online]. NSW Government. Available: http://www.safework.nsw.gov.au/about-us [Accessed].

Akinade, O. O., Oyedele, L. O., Ajayi, S. O., Bilal, M., Alaka, H. A., Owolabi, H. A., Bello, S. A., Jaiyeoba, B. E. \& Kadiri, K. O. 2017. Design for Deconstruction (DfD): Critical success factors for diverting end-of-life waste from landfills. Waste Management, 60, 3-13.

Al-Tmeemy, S. M. H., Abdul-Rahman, H. \& Harun, Z. 2012. Contractors' perception of the use of costs of quality system in Malaysian building construction projects. International Journal of Project Management, 30, 827-838.

Armatys, J., Askham, P., Bennett, L., Cheetham, T., Dawson, M., Dickinson, S., Fortune, J., Griffith, A., Hill, C. \& Kirkwood, J. 2010. The Sheffield Hallam University Built Environment Research Transactions.

Berenson, M., Levine, D., Szabat, K. A. \& Krehbiel, T. C. 2012. Basic business statistics: Concepts and applications, Pearson higher education AU.

Diven, R. J. \& Shaurette, M. 2010. Demolition: Practices, Technology, and Management, Purdue University Press.

Dulaimi, M. F., Ling, F. Y. \& Bajracharya, A. 2003. Organizational motivation and inter-organizational interaction in construction innovation in Singapore. Construction Management and Economics, 21, 307318.

EPHC 2010. National Waste Report. Australia: Environment Protection and Heritage Council.

Forghani, R., Sher, W., Kanjanabootra, S. \& Totoev, Y. 2017. Consequence of waste levy revocation: case study Queensland, Australia.

Huuhka, S., Kaasalainen, T., Hakanen, J. H. \& Lahdensivu, J. 2015. Reusing concrete panels from buildings for building: Potential in Finnish 1970s mass housing. Resources, Conservation and Recycling, 101, 105121.

Jayawardane, A. 1994. Are we aware of the extent of wastage on our building construction sites? Engineer, 20, 41-5.

Khalfan, M., Noor, M., Maqsood, T., Alshanbri, N., Rahmani, F. \& Sagoo, A. 2015. Perceptions towards sustainable construction amongst construction contractors in state of Victoria, Australia. Journal of Economics, Business and Management, 3, 940-947.

Kulatunga, U., Amaratunga, D., Haigh, R. \& Rameezdeen, R. 2006. Attitudes and perceptions of construction workforce on construction waste in Sri Lanka. Management of Environmental Quality: An International Journal, 17, 57-72.

Laefer, D. F. \& Manke, J. P. 2008. Building reuse assessment for sustainable urban reconstruction. Journal of construction engineering and management, 134, 217-227.

Lingard, H., Graham, P. \& Smithers, G. 2000. Employee perceptions of the solid waste management system operating in a large Australian contracting organization: implications for company policy implementation. Construction Management \& Economics, 18, 383-393.

Nakajima, S. \& Russell, M. 2014. Barriers for Deconstruction and Reuse/Recycling of Construction Materials. International Council for Research and Innovation in Building and Construction (CIB).

Osmani, M., Glass, J. \& Price, A. D. 2006. Architect and contractor attitudes to waste minimisation. 
Osmani, M., Glass, J. \& Price, A. D. 2008. Architects' perspectives on construction waste reduction by design. Waste Management, 28, 1147-1158.

Papargyropoulou, E., Lozano, R., Steinberger, J. K., Wright, N. \& Bin Ujang, Z. 2014. The food waste hierarchy as a framework for the management of food surplus and food waste. Journal of Cleaner Production, 76, 106-115.

Peng, C. L., Scorpio, D. E. \& Kibert, C. J. 1997. Strategies for successful construction and demolition waste recycling operations. Construction Management and Economics, 15, 49-58.

Pickin, J. 2013. Analysis of landfill survey data. Waste Management Association of Australia: Blue Environment Pty Ltd.

Randell, P., Pickin, J. \& Grant, B. 2014. Waste generation and resource recovery in Australia Reporting period 2010/11.

Skoyles, E. R. \& Hussey, H. 1974. Wastage of materials on building sites, Building Research Establishment.

Spooncer, F. 1992. Behavioural Studies for Marketing and Business Leckhampton. UK: Stanley Thornes (Publishers) Ltd.(first published 1989).

Teo, M. \& Loosemore, M. 2001. A theory of waste behaviour in the construction industry. Construction Management \& Economics, 19, 741-751.

Teo, M. \& Loosemore, M. Changing the environmental culture of the construction industry. Construction Research Congress: Wind of Change: Integration and Innovation, 2003. 1-8. 